\title{
El caso de Rachida: El complicado camino hacia la igualdad de las mujeres musulmanas en la Francia de la laïcité ${ }^{1}$
}

The case of Rachida: the hard way to equality for muslim women in the secular France

\author{
Guadalupe Calvo García \\ Universidad de Cádiz \\ guadalupe.calvo@uca.es
}

\section{Resumen}

Este artículo surge de un trabajo de investigación titulado "Una mirada a través del pañuelo. Conociendo a las estudiantes francesas de tradición musulmana" desarrollado durante varias estancias en la Université Paris Nanterre, entre el curso 2016-2017 y el 2019-2020, financiadas por el Plan Propio de Investigación de la Universidad de Cádiz. Con él se perseguía escuchar en primera persona a mujeres francesas musulmanas y universitarias, con el fin de mostrarlas como ellas mismas se perciben, evitando los estereotipos y prejuicios dominantes, que habitualmente las llevan a la exclusión. Finalmente, fueron objeto de estudio 10 estudiantes del ámbito de las ciencias sociales dentro de la veintena de edad. Concretamente, en las páginas que siguen desarrollaremos el caso de Rachida, una joven que, sosteniendo un discurso similar al de sus compañeras, destaca por su actitud reflexiva, su espíritu crítico y su compromiso social. De modo que, desde sus experiencias y su análisis de la realidad fundamentado, nos ofrece una perspectiva amplia y profunda de la complicada situación en la que se encuentran las mujeres musulmanas en Francia.

Palabras clave: Mujeres musulmanas, Hiyab, Laicidad, Desigualdad, Educación

\begin{abstract}
This article is based on a research entitled "A glance thru the veil. Getting to know French students with muslim tradition" developed after several stays at the Université Paris Nanterre during academic years 2016-2017 and 2019-2020, sponsored by the Investigations Fund of the University of Cadiz. The goal of this study was to directly listen to college French Muslim women, so as to show how they perceive themselves, avoiding stereotypes and dominant prejudice, whis usually lead them to exclusion. Finally, the investigation was focused on 10
\end{abstract}

${ }^{1}$ Recibido: 05/12/2019 Evaluado: 04/01/2020 Aceptado: 02/04/2020 
students, on or about 20 years of age, related to Social Science studies. We will specifically develop Rachida's case, a young woman that, with a speech similar to that of her companions, stands out for her reflexive attitude, critical spirit and social compromise. Rachida's experiences and grounded analysis of reality offer us a wide, deep and ample, perspective of the muslim women dificult life in France.

Keywords: Muslim women, Hiyab, Secularism, Inequality, Education

\section{Introducción}

Llegamos a la experiencia que relataremos en este artículo gracias a un trabajo de investigación titulado "Una mirada a través del pañuelo. Conociendo a las estudiantes francesa de tradición musulmana", el cual hemos podido desarrollar gracias a diversas estancias en la Université Paris Nanterre financiadas por el Plan Propio de Investigación de la Universidad de Cádiz.

Este trabajo surge tras cierta trayectoria investigadora desde una perspectiva cualitativa, preocupada por escuchar a quienes se encuentran en situación de desigualdad, y centrada fundamentalmente en el ámbito de los estudios de género; tras varios años de impartir una asignatura sobre políticas educativas, en la que resultaba imprescindible reflexionar acerca de obligatoriedad de impartir la religión en nuestras escuelas; y tras una estancia de investigación en la citada universidad del extrarradio parisino, en la que se descubrió una Francia multicultural anteriormente desconocida.

Las circunstancias mencionadas contribuyeron a que nos interesáramos por la laïcité française, que inicialmente nos pareció un modelo bastante deseable y adecuado para favorecer la equidad. No obstante, también fue inevitable prestar atención a los atentados terroristas de carácter yihadistas que durante esa época comenzaron a sucederse en Europa y principalmente en Francia, los cuales nos suscitaban bastantes preguntas. Aunque si hubo un acontecimiento determinante para el comienzo de esta investigación, este fue la prohibición del "burkini" en las playas de algunos municipios franceses durante el verano de 2016.

Obviamente, los antecedentes expuestos nos llevaron a querer leer todas las noticias que los medios de comunicación publicaban al respecto. En ellas descubrimos el principal argumento de los ayuntamientos promotores de la medida: el "burkini" es un signo del radicalismo islámico que tanto daño estaba provocando en el país. Pero también encontramos discursos críticos con la medida adoptada por dichos ayuntamientos: por no orientarse a favorecer la igualdad de las mujeres afectadas, por centrar la atención en las supuestas desigualdades que experimentan las mujeres musulmanas y no en las que experimentan el resto de mujeres, por la humillación que supone que un policía obligue a una mujer a desnudarse en un espacio público, etc. 
La cuestión fue que surgieron gran cantidad de discursos en torno al tema, pero resultaba complicado acceder al de las protagonistas, en correspondencia con la crítica de Adlbi Sibai (2018) que denuncia que la "mujer musulmana con hiyab" es tratada exclusivamente como "sujeto pasivo de estudio" (134). En consecuencia, nuestra experiencia investigadora nos llevó a querer escucharlas, conocerlas y mostrarlas como ellas mismas se perciben; con sus particularidades, en su diversidad, dejando a un lado los estereotipos y prejuicios eurocentristas que, como fuimos descubriendo, las excluyen y les complican la vida.

Por esta razón, decidimos que nuestros sujetos de estudio fueran estudiantes universitarias francesas musulmanas, algunas de las cuales ya habíamos tenido la oportunidad de conocer: chicas con formación académica, insertas en el mundo laboral, comprometidas socialmente muchas de ellas; chicas que abundan en el contexto parisino, pero no parecen ser reconocidas ni valoradas. En este grupo de estudiantes universitarias encontramos a Rachida (nombre ficticio para preservar su anonimato), una mujer que, además de aglutinar todas las características previamente señaladas, destaca por su actitud reflexiva y crítica, su discurso bien fundamentado y su compromiso social; razón por la cual vamos a contar su caso, representativo de los del resto de sus compañeras y que, a su vez, nos ilumina acerca de la difícil situación en la que se encuentran la mayoría de las mujeres musulmanas en la Francia de nuestros días.

\section{Fundamentación teórica}

Una de las principales características de la República Francesa es su läicité, que comienza a atisbarse tras su gran revolución, al proclamarse el 26 de agosto de 1789 la "Declaración de los derechos del hombre y del ciudadano", que en su artículo 10 garantiza la libertad religiosa siempre que no se altere el orden público. Tras cierto desarrollo normativo en esa línea, es la Ley de 9 de diciembre de 1905 la que realmente confirma la separación entre la Iglesia y el Estado, garantizando en su artículo 1 la libertad de culto y estableciendo en el 2 el no reconocimiento y la no financiación por parte del estado de ninguna religión. Posteriormente, es la Constitución de 1946 la que denomina por primera vez a Francia como un estado laico, en el que, según Bianco (2016) dominó una perspectiva que rechazaba una laïcité anticlerical $\mathrm{o}$ antirreligiosa.

El mismo autor explica que durante años el islam estuvo fuera de debate y que Francia rehusó incluso a imponer la laïcité en Argelia mientras, como colonia, llego a formar parte de la República. Señala que el principal conflicto en este sentido se focalizaba en las escuelas católicas privadas, que comenzaron a recibir financiación por parte del estado.

Es en 1989 cuando el conflicto vira hacia el islam y, concretamente, hacia el hiyab, por ser el signo más visible vinculado a dicha religión. La polémica explota cuando el 18 de septiembre de 1989 se prohíbe a tres chicas musulmanas asistir a la escuela con foulard. A partir de ahí todo evoluciona de manera que el 15 de marzo de 2004 se aprueba la ley que prohíbe los signos ostentatorios religiosos en las escuelas e institutos, y el 11 de octubre de 2020, otra que prohíbe llevar oculta la cara en los espacios públicos.

Por otra parte, en 2005 se suceden las revueltas en la banliue (suburbios de las afueras) parisina, donde se concentra gran parte de la población de origen extranjero y con quienes el

$\mathrm{N}^{\mathrm{o}} 8$, 2020. Página 63 
gobierno francés ha llevado a cabo políticas de integración asimilacionistas (Ramírez y Mijares, 2005). El fenómeno de los suburbios de París ha interesado especialmente a Kepel, quien, a pesar de destacar su complejidad por la gran cantidad de factores que intervienen en él, establece que es imprescindible que la población de estas áreas pueda creer en los valores de la nación a través de, al menos, el acceso al empleo y la educación (2011). En este sentido, Eseverri $(2007,196)$ defiende que Francia respeta a las personas migrantes siempre que estas respeten el laicismo, que tiene el objetivo promover la igualdad y que "a fuerza de querer "igualar", genera el efecto inverso: una diferenciación y una discriminación hacia "lo diferente"'; y que este es el principal problema de los y las jóvenes de la banlieu, especialmente de los que provienen de las antiguas colonias, de los que (inconscientemente) la sociedad espera que ocupen las mismas posiciones que ocupaban sus padres y madres. Esta autora, sin rechazar la propuesta de Kepel, aboga por implantar nuevos modelos de comunicación y participación ciudadana.

No obstante, como anunciábamos, entre esta población de origen extranjero que en muchos casos vive en la banlieu, son las mujeres musulmanas provenientes de las antiguas colonias francesas y que usan el hiyab "la Otra por antonomasia" (en palabras de Adlbi Sibai, 2018, 134) y, consecuentemente, las que mayores dificultades encuentran. En primer lugar, porque al constituir dicho hiyab un signo vinculado a la cultura religiosa tan visible, no está permitido en ciertos espacios públicos (normalmente, educativos o laborales), lo que las obliga a elegir entre mantener su decisión y no acceder a los mismos, o acceder y tener que renunciar a sus convicciones. En segundo lugar, porque su situación se complica al no ser ni siquiera aceptadas por ciertos sectores del feminismo; ni por algunas feministas occidentales, para quienes "el hiyab representa la opresión de las mujeres: es un mandato patriarcal que niega a las mujeres el derecho a controlar sus cuerpos" (Lambrabet, 2016, 40); ni por algunas feministas provenientes de países con regímenes islámicos, que las acusan, entre otras cosas: de usar el pañuelo para llamar la atención (Djavann, 2003); de tener lavado el cerebro (Haddad, como se citó en LD/Agencias, 2019, 29 de septiembre); o de no poder ser feministas, por considerar que el feminismo no puede ir unido a las religiones, que nunca propondrán cambios en las estructuras de poder (Armanian, 2017); y especialmente, no puede ir en consonancia con ciertos mandatos de los fundamentalismos islámicos, que están imponiendo normas y prácticas que no habían existido previamente en los contextos culturales musulmanas (Hamido Yahia, 2019).

Sin embargo, como bien muestra Ali (2012), también hay bastantes feministas que señalan los aspectos positivos del conocido como feminismo islámico que:

defiende que la verdadera liberación de la mujer (musulmana, por supuesto) no está en el abandono de la propia cultura -entendida, claro, en términos religiosos- y en la adopción de valores extranjeros, sino en la vuelta al islam, en la aplicación de la sharía, una vez, eso sí, depurada de todas las falsas interpretaciones acumuladas tras siglos de exégesis coránica masculina y patriarcal (Paradela, 2014, 5).

Debido a que, como indica Andujar (2012), cuanto más nos alejamos de la época en la que se escribieron los textos sagrados originales, más excluidas están las mujeres. Por esa razón, como se deriva de la definición ofrecida por Paradela, el feminismo islámico trata de luchar no solo contra el patriarcado sino también contra el colonialismo; motivo por el cual muchas 
mujeres musulmanas han antepuesto su identidad religiosa a todas las demás, ha sido asumido por muchas europeas migrantes de segunda o tercera generación, y suele ser apoyado por los movimientos de izquierda (lo que duele especialmente a Hamino Yahia). Para Ali (2012) la clave está en que las mujeres musulmanas, muy diversas entre sí, luchen por la igualdad en función de las problemáticas que les afectan.

Pero a pesar de que bastantes musulmanas europeas asumen esta perspectiva del islam con aspectos liberadores, como bien señalan Andujar (2012), siguiendo a Palacios, y Adlbi Sibai (2018), los medios de comunicación siguen ofreciendo una imagen sensacionalista y negativa de ellas (esa que tanto se ocupó de contrarrestar Mernissi, 2004, 2006). Según entienden las autoras, lo hacen: para mantener el mito de la sumisión de estas, que justifica las políticas intervencionistas; y para mantener la imagen de la "alteridad", de que son diferentes a nosotros.

En contra de la imagen que difunden los medios de las mujeres musulmanas, Andujar (2014) aludiendo a Silvestri (2008), muestra que estas en occidente son muy diversas (no existen dos grupos enfrentados de modernas/feministas contra conservadoras/retrógradas), que la mayoría se identifican como europeas, que el paso por el sistema educativo las ha emancipado y que ahora ocupan nuevos papeles y reinterpretan los textos religiosos para evitar sus restricciones, que reivindican los derechos democráticos, y reclaman ser respetadas tal y como son sin tener que elegir entre ser musulmanas y ser europeas. En contra de la división y el enfrentamiento entre musulmanas que trabajan por la igualdad, Bienaimé (2016) apuesta por un feminismo de hermandad, solidario e interseccional.

\section{Metodología de investigación}

Nuestro trabajo de investigación se ha desarrollado fundamentalmente durante cuatro estancias de tres meses en Paris (entre noviembre y febrero, desde el curso académico 20162017 hasta el 2019-2020) realizadas en el seno de un grupo de investigación de la Université Paris Nanterre, cuyos miembros (parte de ellos) nos proporcionaros las primeras informaciones imprescindibles para acercarnos al tema a través de conversaciones informales, nos pusieron en contacto con las primeras estudiantes sujetos de estudio que entrevistamos (que cursaban un master que coordinan), y, por supuesto, con su acogida nos ofrecieron la posibilidad de llevar a cabo la observación etnográfica imprescindible para conocer desde dentro y en profundidad el contexto objeto de estudio.

Una profesora y un profesor de este grupo de investigación nos facilitaron este trabajo a pesar de que abordar la cuestión que nos ocupa resulta bastante controvertido en Francia, precisamente, debido a la laïcité tan estrictamente implantada en las instituciones públicas y, especialmente, en las educativas. Cabe destacar algunos de los inconvenientes con los que ambas partes nos encontramos: ciertos miembros del grupo rechazaron colaborar invitando a sus alumnas a participar en el estudio, argumentado que la religión es un tema privado; además, solicitaron que las conversaciones con las chicas se desarrollaran fuera del contexto institucional de la universidad; incluso el compañero dispuesto a ayudarnos se encontró con dificultades para seleccionar el momento adecuado para animar a sus alumnas a participar en el estudio, debido a que los temas religiosos habitualmente dan lugar a desencuentros. 
Finalmente, nuestras sujetos de estudio han sido 10 estudiantes universitarias; todas de titulaciones del ámbito de las Ciencias Sociales; en la veintena de edad; francesas de origen africano (magrebí o subsahariano), a excepción de una cuyos ascendientes también era franceses; con hiyab, a excepción de tres: una llevaba turbante por el momento, otras dos no llevaban nada, aunque una de ellas se lo puso poco después de nuestra entrevista.

A estas chicas las hemos conocido gracias al desarrollo de entrevistas semiestructuradas (una con cada una y dos con una de ellas), a la puesta en marcha de un grupo focal con cinco de las mismas, y al mantenimiento de múltiples conversaciones informales en la universidad (antes y después de las entrevistas, y a través de Whatsapp). Las conversaciones informales, de enorme valor para esta investigación, al realizarse en un contexto ajeno a las personas que investigan, se llevaron a cabo también con profesorado universitario, y con otras y otros estudiantes de doctorado, de máster y de grado.

En cuanto a los contactos con Rachida, con ella mantuvimos una entrevista en la biblioteca de la universidad que se alargó cuatro horas, también se han establecido gran cantidad de conversaciones informales y, además, participó en el grupo focal junto a cuatro de sus compañeras de máster. De ella nos fascina su intelectualidad, que da lugar a un discurso reflexivo y crítico sustentado en conocimientos teóricos que también guían su manera de actuar en la vida.

Las cualidades mencionadas hacen que la información proporcionada por esta estudiante resulte especialmente valiosa porque, aún relatando sus experiencias como francesa musulmana desde una perspectiva coincidente con la del resto de sus compañeras, ella es capaz de, partiendo de su caso y del de las mujeres de su familia, ofrecer un análisis bien argumentado de la sociedad francesa y de la posición desigual e injusta a la que relega a las mujeres musulmanas.

Y lo expuesto sucede porque Rachida pone la educación en el centro, lo repite continuamente: necesita aprender de fuentes primarias y acompañada de personas referentes en la materia; necesita encontrar una explicación científica a todas las cuestiones que le preocupa; e identifica la educación como la herramienta fundamental para poder reivindicar la igualdad de derechos y para poder valorar la diversidad existente en las personas.

\section{Rachida: su perspectiva personal y profesional sobre las mujeres musulmanas en Francia}

Rachida es una chica francesa de 26 años (que tenía esa edad en el momento de nuestras conversaciones), recién casada y estudiante de un máster de educación en la Université Paris Nanterre. Casi toda su vida ha vivido a las afueras de París, en la banlieu, con sus padres y su hermana, excepto 6 o 7 años durante los cuales se trasladó con su madre a Marruecos (de donde procede toda su familia) para cuidar a su abuela.

Ha llegado a ser universitaria casi fortuitamente, gracias a la ilusión y el apoyo de su madre, quien después de que suspendiera su examen de Bachillerato de Ciencias Sociales y Económicas a la primera, la animó a que volviera a intentarlo "por libre", sin asistir a clase. Rachida cuenta que en esa época comenzó a dedicarse a trabajar en animación, que no

No 8, 2020. Página 66 
estudió, que solo realizó los exámenes por complacer a su madre, pero que, sorprendentemente, al acudir relajada los superó.

Entonces inició sus estudios universitarios de Sociología, que le encanta, y el tercer año cursó un doble título de Sociología y Ciencias de la Educación, que le resultó muy útil para el desarrollo de su trabajo en el ámbito de la animación. Posteriormente, se presentó a las oposiciones para trabajar como profesora, pero suspendió; de ese modo llegó al máster de intervención educativa en contextos desfavorecidos, que comprende una serie de contenidos que son los que más le motivan.

Respecto a su familia, la presenta señalando que cuenta con su pequeña familia (su madre, su padre y su hermana de 17 años), pero que realmente tiene una gran familia (la familia extensa de la que proviene sus progenitores). Su padre, aunque es de nacionalidad marroquí, vive en Francia desde su adolescencia; mientras que su madre, se trasladó a ese país tras su matrimonio. Ella tiene formación como costurera, y él ha trabajado fundamentalmente como obrero, aunque también ha hecho un poco de todo: "Il a travaillé un peu dans tout, dans des différents magasins, et il a travaillé aussi en tant que gardien, agent de sécurité, etc. Puis après, il avait travaillé en tant que commerçant avec son père”.

Además, nuestra protagonista cuenta con su reciente marido, un compañero de trabajo con el que tenía mucha afinidad y al que sentía complementario en lo académico, ya que a ella se la dan bien las letras, mientras que él, las ciencias. Confiesa que, desafiando los patrones tradicionales, fue ella la que le pidió matrimonio, y que desde ese momento se siente muy feliz.

\section{El hiyab en su familia}

Rachida explica que su madre usa el hiyab en ocasiones, con un sentido cultural, porque ella ha crecido en Marruecos y allí se suele utilizar independientemente de si se es religiosa o no; se usa como complemento de la vestimenta tradicional que suelen realizar las costureras con las telas elegidas por sus clientas. Puntualiza que fue al llegar a Francia cuando su madre se dio cuenta de que con el hiyab la miraban diferente, y dejó de utilizarlo siempre: " $C$ 'est en arrivant ici en France qu'elle a vu que c'était... que les gens, ils avaient un regard différent sur ça, puisqu'elle l'enlève et elle le met'"

Ella comenzó a utilizar esta prenda (que combina con exquisita elegancia con el resto de su vestimenta) solo seis meses atrás, aunque después de tres años de reflexión sobre lo que la decisión de llevarla implicaría. No obstante, una vez que se decidió, se puso el hiyab completo, no siguió un proceso de adaptación progresivo como otras compañeras quienes, por ejemplo, comenzaron llevando un turbante u otros elementos más propios de la cultura occidental, que cumplen una función similar a la del hiyab, pero no generan tanto rechazo social. Considera que, aunque su cambio fue radical, quienes la conocían bien, lo esperaban y no se sorprendieron.

Mais moi, c'est 3 ans de réflexion en fait. Ça fait 3 ans que j'ai envie de le porter. Pour mes proches, ils ont pas été choqués, mes copines en tout ça, elles ont pas été vraiment choqués en me voyant parce qu'ils me connaissaient. 
Señala la gran diferencia entre su madre y ella; su madre le ha enseñado los aspectos más básicos del islam, pero no es muy religiosa y no siente la necesidad de saber más; ella, sin embargo, siempre ha sido curiosa, ha pasado por el sistema escolar y necesita demostración para creer en las cosas que se le dicen: "Pour elle, elle a pas besoin de chercher plus, ça lui suffisait. Mais moi qui ai un profil un peu différent, je suis passée par le système scolaire, donc on a toujours besoin de démonstration".

\section{Su formación teórica acerca de la religión}

Por las razones argumentadas previamente, las reflexiones de Rachida acerca del uso del hiyab estuvieron acompañadas por una formación en un instituto de ciencias religiosas, ya que ella necesitaba saber más, necesitaba dar respuesta a ciertas preguntas y quería hacerlo junto a personas con formación sobre el tema y reconocimiento, y recurriendo a las fuentes primarias. Subraya que en estas descubrió un respeto y una libertad para las mujeres que le impresionó. Le disgusta que muchas personas que se dicen religiosas, se conformen con saber lo que les cuentan sus amistades o con lo que encuentran en Internet, donde a veces pueden leerse barbaridades que, en ocasiones, dan miedo.

Quand on veut apprendre quelque chose, il faut aller à la source et pas se renseigner chez monsieur ou madame ou l'épicier. C'est comme tout en fait parce que la... certains, la religion, pour eux, ils veulent apprendre la religion, donc ils vont à leur copain ou la copine, et c'est important d'avoir quelqu'un qui a vraiment la science. C'est un peu comme tout, non ?

Pero no solo los citados estudios han contribuido a que aumente la espiritualidad de nuestra joven, ella afirma que han sido sus estudios universitarios los que más la han acercado a Dios, porque le han proporcionado las herramientas para llevar a cabo reflexiones intelectuales que le han permitido comprender muchos aspectos sobre la religión y descubrir la coherencia interna de esta. Para ella, la ciencia y la investigación no están reñidas con la religión, "et je n'ai jamais trouvé de contradiction".

\section{Su espiritualidad compartida con personas diversas}

A Rachida le hizo mucho bien estar en ese instituto, porque le permitió aclarar ciertas dudas, acceder a ciertas referencias bibliográficas y, sobre todo, conocer a personas con las que se identificaba, compartir sus problemas, saber cómo los superan, etc. A ella le resulta complicado en ocasiones ser una persona espiritual en el mundo actual, en Francia.

Por esta razón, durante un tiempo ha intentado formar un grupo interreligioso (al estilo de la asociación Coexister $^{2}$ ) con amistades que profesan diferentes creencias; las propias del Islam, del cristianismo o del judaísmo. Esto es posible en su ciudad de las afueras de París, debido a la gran diversidad cultural existente. Además, no le supone ningún conflicto, porque concibe las religiones en relación, como un continuo.

\footnotetext{
${ }^{2}$ https://www.coexister.fr/
} 
Durante una temporada estuvo en conversaciones para llevar a cabo su proyecto en una sinagoga, pero finalmente no se lo permitieron. Considera que, aunque resulta más complicado conocer a las personas judías, y hay más afinidad entre las musulmanas y las cristianas, todas las personas religiosas (y, en definitiva, espirituales) buscan cosas parecidas, todas se parecen y se enfrentan a dificultades similares.

c'était quand même des gens qui étaient en tout cas spirituels et religieux, qui étaient... et en fait, on s'est rendu compte qu'on avait des choses qui nous rassemblent. Mais il y a des choses qui nous... bah qui nous divisent, qui nous différencient je dirais. Et en même temps, finalement, on vit les mêmes difficultés qu'on soit musulman ou chrétien

\section{Los estigmas con los que convive}

Sin embargo, la joven siente que cuando sale de esos círculos de intercambio y reflexión, los medios de comunicación los muestran como si fueran grupos opuestos "j'ai l'impression qu'il y a eux et nous". Al proyectarse esa imagen de la comunidad musulmana que vive en banlieu, Rachida siente que reina el desconocimiento acerca de la misma y que la sociedad está "bourrés de préjugés"; lo percibe en las preguntas y los comentarios que le hacen, por ejemplo, en la facultad: "Oh la la ! Vivre en banlieue, c'est très difficile”(...) Comment ça se passe en banlieue? On t'a jamais agressée?(...) Je mettrai jamais les pieds là-bas”. Por el contrario, a ella le encanta vivir ahí, por la mezcla étnica y cultural, porque las relaciones son más cercanas y se habla con naturalidad acerca del origen de cada persona, de su religión, etc.; y cuando empezó a desenvolverse en París, se dio cuenta de que allí había mucha más distancia entre las personas y de que ella reunía bastantes características que la estigmatizaban: mujer, de origen magrebí, del extrarradio, musulmana... además percibió el miedo y el desconcierto cuando decidió ponerse su hiyab: "Qu'est-ce qui s'est passé ? Estce que ça va? Est-ce qu'on t'a forcée?

\section{Las mujeres musulmanas y la lä̈cité}

Rachida desconocía que el objetivo de la läcité propia del estado francés era que cada ciudadano y cada ciudadana pudiera vivir sus creencias libremente y desde el respeto a las otras (sin imposiciones ni jerarquías), hasta que comenzó sus estudios universitarios; previamente, pensaba que esta perseguía impedirles practicar su religión. Ella lo entendía así porque en la práctica es eso los que observa, que las personas musulmanas encuentran muchos impedimentos para vivir su religiosidad; especialmente las mujeres que usan el hiyab, que es un signo tan visible; quienes tienen que renunciar a él en sus contextos profesionales y para acceder a ciertas formaciones. La joven cree que el discurso dominante al respecto es bastante ambiguo, porque afirma que la religión impide a las mujeres tener libertada de pensamiento, de elección, ser autónomas, etc., y al mismo tiempo les cierra las puertas del saber impidiéndoles cursar ciertos estudios sin renunciar a su elección; lo que a su vez les dificulta acceder al espacio público, a ciertos derechos y, finalmente, las condena a estar encerradas, a no poder construirse un futuro, a no poder elegir libremente. Considera que hay una contradicción entre los objetivos que dicen querer conseguir y las medidas que ponen en marcha. 
Si on part du principe que c'est contraint, il faut lui laisser la chance de pouvoir aller dans des lieux pour qu'elles puissent peut-être étudier, comprendre et faire son choix plus librement. Mais si tu... si on leur ferme ces portes-là, bah c'est tout le contraire en fait.

\section{Las mujeres musulmanas y el feminismo}

Por otra parte, Rachida tampoco entiende ciertos discursos feministas, porque le parece que no defienden los derechos de todas las mujeres y, finalmente, no defienden los derechos humanos. Percibe un feminismo mediático con el que todas deben corresponderse para que no se considere que están contra las mujeres. Y las mujeres musulmanas que usan el hiyab no encaja en dicho modelo, por lo que la ola de feminismo islámico existente no cuenta con reconocimiento: "Non, tu peux pas être musulmane et féministe puisque tu es contre". Le resulta ridículo que se piense que por llevar hiyab no se es libre y no se puede defender los derechos de las mujeres.

No entiende que mujeres que han luchados tanto para poder trabajar, para heredar, para tener su propia cuenta bancaria, para vestirse como quieren, ahora luchen por lo contrario y no permitan que otras mujeres se expresen y vivan libremente. Si luchamos por la libertad, debe ser por la libertad de todas las personas, no solo por la de quienes entienden la libertad como nosotras, "tu veux pas imposer ta liberté aux autres".

\section{Las mujeres musulmanas en los medios de comunicación}

Piensa que domina esa imagen de las mujeres musulmanas porque no se les deja espacios para expresarse en los medios de comunicación y sus voces no se escuchan. Rachida denuncia que siempre se invite a hombres para que hablen por ellas y, en todo caso, a mujeres de contextos desfavorecidos que se encuentran en situaciones difíciles, cuyos testimonios contribuyen a alimentar la imagen sobre las musulmanas y sobre el hiyab que les interesa difundir (de hecho, detecta tanto periodismo sensacionalista que ya no le extraña el miedo a las personas musulmanas, ni el racismo, ni el apoyo a Le Pen).

Subraya que, incluso, se ofrece una imagen homogénea de todas las mujeres musulmanas, como si todas experimentaran las mismas situaciones, como si todas defendieran las situaciones injustas que experimentan las mujeres en ciertos países islámicos, y como si toda su identidad la abarcara la religión. Rachida reivindica que las mujeres musulmanas son también amigas, hermanas, estudiantes, trabajadoras... que son multidimensionales y plurales; que no es igual una mujer que vive en el campo que la que vive en la ciudad, una que ha crecido en Francia que otra que ha crecido en Afganistán. " $C$ 'est qu'il faut toujours prendre les choses dans leur contexte. Il y a des femmes... il n'y a pas une femme musulmane, il y a des femmes musulmanes".

\section{La invisibilización de los logros y las aportaciones de las mujeres musulmanas}

A la imagen estereotipada que se difunde de las mujeres musulmanas, se le suma el hecho de que, al no poder estas usar el hiyab en ciertos espacios públicos, se invisibiliza que ellas también desarrollan muchas actividades que contribuyen positivamente a la sociedad. 
Rachida expone que, en muchos trabajos, los propios compañeros y las compañeras desconocen que sus colegas son musulmanas, debido a que estas deben esconder o quitarse si hiyab, y no se lo vuelven a poner hasta que parten hacia sus casas, con miedo a que alguien las reconozca, "c'est comme si tu avais fait un crime".

En parte, entiende que una maestra no lleve el hiyab en la escuela, porque constituye un referente para su alumnado y debe ser imparcial; pero, al mismo tiempo, se plantea que si todo el mundo se acostumbrara a ver que las personas somos diversas, "qu'il y a des gens qui est musulman, pas musulman, foulard, pas foulard, qui est noir, qui est blanc, qu'il y en a un peu partout", esta diversidad se naturalizaría y se respetaría, y sería la mejor manera de conseguir ese "vivre ensemble" que, en teoría, persigue la laïcité.

Aunque a la sociedad francesa no suele extrañarle ni molestarle no ver a mujeres musulmanas en contextos educativos y laborales, parece que sí le preocupa que estas no frecuenten los espacios en los que habitualmente están los hombres. A Rachida también le disgusta escuchar continuamente que deberían estar en la calle o en los cafés y que eso implicaría mayor igualdad entre mujeres y hombres:

«Oh! Regardez dans la place publique, il y a très peu de femmes. Oh là, là ! Qu'estce qui se passe? Il n'y a pas assez de mixité. Ah non! C'est un problème. Il faut qu'il $y$ ait plus d'égalité homme-femme, plus de mixité. »

Ella defiende que si se conociera la situación con mayor profundidad, se vería que ellas cuentan con más titulaciones académicas y se insertan más fácilmente en el mucho profesional. Afirma que la cuestión no es, por qué no abunda la "mixité" en los espacios públicos, sino, cómo podrían alcanzar esos hombres el estatus académico y profesional de las mujeres.

\section{La evolución de las mujeres musulmanas en Francia}

Rachida es consciente de que la posición de las musulmanas de segunda o tercera generación, como ella, es muy diferente de la que tuvieron las de las primeras generaciones, como su madre; ha tenido conversaciones al respecto incluso con uno de sus profesores de sociología.

Sus abuelos llegaron a Francia desde un contexto de guerra con intención de ganar algo de dinero y volver a Marruecos, no conocían la cultura ni el idioma, tenían miedo de las instituciones y preferían ser lo más discretos posible; “C'est des gens qui ne sont pas dans la revendication". Además, formaban parte del "mundo invisible", desempeñaban trabajos no valorados: obreros, mujeres de la limpieza... su abuelo rezaba en el cuarto de la basura y no se atrevía a demandar un espacio mejor a pesar de que tenía derecho a ello; en esa situación, a nadie le importaba si una mujer llevaba hiyab o no.

La generación de Rachida ha nacido en Francia y se siente en su casa, por lo tanto, no duda en reivindicar, por ejemplo, tener comida halal; pero se encuentra con problemas diferentes a los de la generación anterior, porque ahora sí ocupan posiciones visibles, al mismo nivel que quienes tienen origen francés, y en esa situación sí molesta el hiyab: “quelqu’un qui

№ 8, 2020. Página| 71 
vient avec toi dans le bureau, qui soit au même niveau que toi qui a le voile, là, ça pose problème".

Ella tiene claro que solo demandan ser respetadas y tener los mismos derechos que las demás personas, porque en la escuela les han hecho creer que había "fraternité, égalité, liberté". Entonces, no entiende por qué debería dejar de usar una prenda que le hace sentirse bien, para que sean las otras personas las que se sientan bien.

\section{No es el hiyab el que limita la libertad, sino la falta de educación}

Quand je vois qu'ils sont là et qu'ils disent : «Oh ! Non, pas le foulard-là, pas le foulard-là. » Je me dis : « Mais arrêtez, il faut donner la chance à chacun de pouvoir étudier, pour se construire. »

Como se ha puesto de manifiesto en todo momento, para Rachida lo más importante es la educación. Para ella es fundamental construirse intelectualmente, contar con un bagaje cultural y ser capaz de reflexionar para tomar decisiones en la vida. También, para tener criterios para seleccionar la información y no creer cualquier cosa que aparezca en los medios de comunicación o en Internet. Está convencida de que es la educación lo que falta a las personas islamistas radicalizadas.

Además, a los niños y a las niñas musulmanes les faltan referentes positivos, deberían tener como modelos a personas adultas musulmanas profesionales, que se dedican a la medicina, al derecho, a la educación; y no construir sus identidades casi exclusivamente a partir de los modelos personales estereotipados que muestran los medios de comunicación. Ha constatado esto en las clases de refuerzo escolar que imparte, donde sus alumnos y sus alumnas le dicen: “Oui mais de toute façon, on n'y arrivera jamais. Puis, on ne veut pas de nous".

\section{Conclusión}

Las experiencias de Rachida; joven francesa de origen marroquí, estudiante de un máster de Ciencias de la Educación, educadora de profesión, comprometida socialmente, espiritual y musulmana; nos ofrecen una panorámica bastante amplia, reflexiva y crítica acerca de la situación complicada en la que se encuentran muchas mujeres musulmanas en el contexto francés.

Nos muestra las diferencias entre su madre, emigrante de primera generación, y ella, de segunda, en el uso del hiyab; una lo utiliza porque es parte de su cultura y no tiene inconveniente en quitárselo cuando considera que este puede acarrearle problemas; y la otra lo porta con convicción religiosa, tras un largo proceso de formación y reflexión.

Igualmente, nos revela que ella, una estudiante universitaria, para aceptar y asumir la religión propia de su cultura de origen, ha necesitado estudiarla junto a personas con una formación académica específica sobre la misma y recurriendo a las fuentes primarias, del mismo modo que aprende en el resto de ámbitos de su vida. A su vez, destaca que sus estudios universitarios le han proporciona las herramientas necesarias para profundizar en el 
conocimiento del islam, por lo que no encuentra contradicciones entre la religión y la ciencia, sino complementariedad; al igual que Andujar (2014) y Adlbi Sibai (2018).

Además, desmonta la idea tan extendida del enfrentamiento entre religiones, al exponer que comparte su espiritualidad con amistades con distintas creencias, y que considera que hay muchos aspectos en común entre dichas personas con diferentes creencias y entre las propias religiones. Como defienden las dos autoras previamente mencionadas, son los discursos que se difunden desde diferentes estructura de poder los que construyen la alteridad.

A pesar de todas las cualidades y planteamientos positivos que acumula Rachida, su relato también refleja que reúne suficientes características para ser estigmatizada y valorada en función de los estereotipos y prejuicios dominantes acerca de las personas musulmanas de origen árabe que viven en el extrarradio, en línea con Eseverri (2007).

Pero el relato de Rachida no se centra exclusivamente en su propia experiencia, sino que incluye reflexiones acerca de la situación general de las mujeres musulmanas en Francia, un país que se caracterizado por la laïcité. Para nuestra protagonista, esta laïcité impulsada con el fin de favorecer la igualdad, la libertad y la fraternidad, en la práctica limita el desarrollo académico y profesional de las mujeres que han decidido llevar el hiyab (como bien se refleja en nuestra fundamentación teórica), contradiciendo así los citados principios que el propio estado francés promulga.

También es crítica Rachida con ciertos discursos feministas que defienden un único modelo de ser mujer; en el que, obviamente, no encajan las mujeres que usan el hiyab; y los que no reconocen el "feminismo islámico", como ocurre con Armanian (2017) o Hamido Yahia (2019).

Igualmente, le disgusta el papel de los medios de comunicación (coincidiendo de nuevo con Andujar, 2014 y Adlbi Sibai, 2018), que ofrecen una imagen de las musulmanas homogénea y estereotipada, la cual no puede ser contrarrestadas si las mujeres que profesan esta religión no pueden llevar el hiyab (y por lo tanto no pueden ser identificadas) en sus centros de estudios o de trabajo, cuando contribuyen más directamente al bienestar de la sociedad. Al respecto, Rachida defiende que si, especialmente, las niñas y los niños vieran habitualmente el hiyab, igual que otros muchos elementos propios de la religión o de la cultura de las personas, se acostumbrarían sin problema a la diversidad.

En este sentido, la joven vuelve a distinguir entre las primeras generaciones de migrantes y las siguientes (desde un planteamiento similar al de Eseverri, 2007), ubicando a las primeras en el "mundo invisible", debido a que llegaron a Francia sin conocer el idioma ni sus derechos, para conseguir dinero realizando trabajos no valorados; sin embargo, su generación es visibles y nació en Francia, y sabe que le corresponde los mismos derechos que al resto de la ciudadanía.

Finalmente, resumiendo el posicionamiento de Rachida, podemos afirmar que aún queda camino por recorrer para que las mujeres musulmanas consigan la igualdad en el contexto francés. Que, en su caso, a las desigualdades que experimentamos las mujeres en general, se le suman los estereotipos y prejuicios que circulan en occidente acerca de las personas 
musulmanas, de las extranjeras (aunque muchas no lo sean), de las que viven en el extrarradio, etc.; el rechazo de ciertas perspectivas feministas a que se pueda luchar por la igualdad desde un posicionamiento religioso; las restricciones propias de la laïcité française, que les dificultan el acceso a la educación y al empleo si deciden llevar el hiyab. Por esto defendemos que el camino hacia la igualdad de estas mujeres pasa inexorablemente por el acceso de la población en general a referentes positivos de las mismas, para que dejen de sufrir el rechazo y la violencia; y por el acceso de ellas a la educación y al empleo, para que puedan decidir con libertad sobre sus vidas.

\section{Referencias}

Adlbi Sibai, Sirin (2018). La cárcel del feminismo. Hacia un pensamiento islámico decolonial. Akal / Inter Pares.

Ali, Zahara (2012). Feminismes islamiques. La fabrique editions.

Andujar, Natalia (2012). Realidades y retos de las musulmanas en occidente. Journal of the European Society of women in Theological Research, 20, 39-57

Armanian, Nazanin (2017, 5 de enero). Los feminismos religiosos no son feminismos. Ara. Recuperado de: https://n9.cl/07mxw

Bianco, Jean-Louis (2016). La France est-elle lä̈que? Les editions de l'atelier

Bienaimé, Charlotte (2016). Feministes du monde árabe. Les arènes.

Constitution. (1946, 27 de octubre) République Française. https://n9.cl/obvtf

Déclaration des Droits de l'Homme et du Citoyen. (1789, 26 de agosto). Assemblée Nationale Française. https://n9.cl/wbyg

Djavann, Chahdortt (2003). Bas les voiles! Folio

Eseverri Mayer, Cecilia (2007). La "revuelta urbana" de los hijos de los inmigrantes en Francia. Migraciones internacionales, 4(2), 189-200. https://n9.cl/4h6u2

Hamido Yahia, Mimunt (2019). Coda: críticas no tan veladas. Araucaria. Revista Iberoamericana de Filosofía, Política, Humanidades y Relaciones Internacionales, 21(41), 527-535. Recuperado de: https://n9.cl/iopw

Kepel, Gilles (2011). Banlieu de la République. Dossier de Prese Institut Montaigne

Lamrabet, Asam (2016). El velo (hiyab) de las mujeres musulmanas: entre la ideología colonialista y el discurso islámico: una visión decolonial. En Ramón Grosfoguel (Comp.). Feminismos islámicos (39-61). Gobiernos Bolivariano de Venezuela. Ministerio del Poder Popular para la Cultura 
LD/Agencias (2019, 29 de septiembre). Joumana Haddad: "Las mujeres árabes llevan hiyab porque les han lavado el cerebro". Libertad digital. https://cutt.ly/dcP9KS0

Loi du 9 décembre 1905 concernant la séparation des Eglises et de l'Etat. (1905, 9 de diciembre). République Française. https://cutt.ly/4cP3rwl

Loi $\mathrm{n}^{\circ}$ 2004-228 du 15 mars 2004 encadrant, en application du principe de laïcité, le port de signes ou de tenues manifestant une appartenance religieuse dans les écoles, collèges et lycées publics. République Française (2004, 15 de marzo). https://cutt.ly/hcP3bf6

Mernissi, Fatema (2004). Las sultanas olvidadas. El Aleph Editores.

Mernissi, Fatema (2006). El harén en occidente. Espasa Calpe.

Paradela Alonso, Nieves (2014). El feminismo árabe y su lucha por los derechos de la mujer. Encuentros Multidisciplinares 46, 1-7. https://cutt.ly/wcP31Re

Ramírez, Ángeles y Mijares, Laura (2005). Gestión del islam y de la inmigración en Europa: tres estudios de caso. Migraciones (18), 77-104. https://cutt.ly/ucP8TAE 